\title{
دور الزكاة المنتجة في خدمة المجتمع و نقصان الفقراء وتحسين الاقتصاد الاندونيسي
}

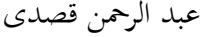

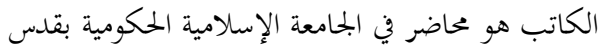

email: abdurrohmankasdi@stainkudus.ac.id

التجريد

مُحدف هذه المقالة تبيين دور الزكاة المنتجة في تحفيف الفقر وتحسين اقتصاد الختمع الاندونيسي.

وهذه الدراسة مستندة على أساس البحث الميداني باستخدام المنهج الظواهري. وأما طريقة تحليل البيانات

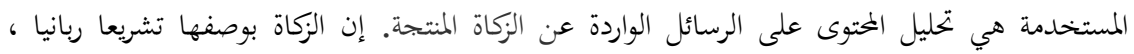

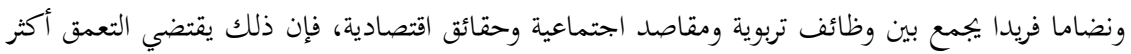

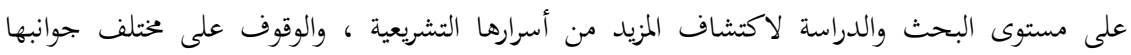

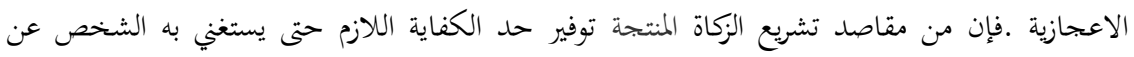

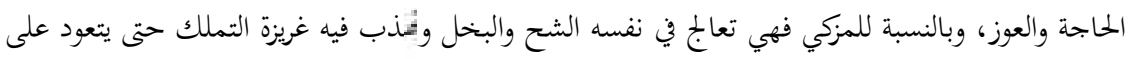

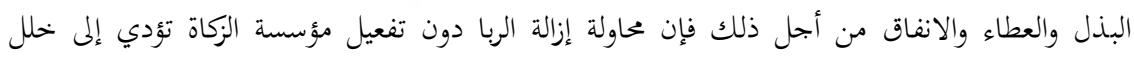

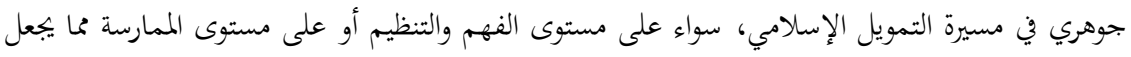

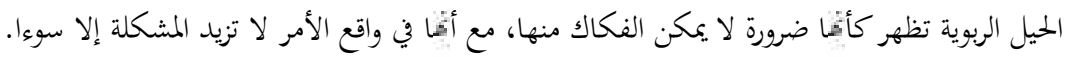
الكلمات الرئيسية: الزكاة المنتجة، نقصان الفقر، تحسين اقتصاد، الجزتمع

\begin{abstract}
This article aims at showing the role of productive zakat in reduce poverty and improving the economy of Indonesian society. This study is based on field research using the phenomenological approach. The method of data analysis used the analysis of the content on the messages received
\end{abstract}


from the productive zakat. Zakat as a religious law, and a unique unity that combines educational functions with social purposes and economic realities require further study to discover more of its legislative secrets and to find out about its various miraculous aspects. One of the purposes of zakat legislation is to provide the necessary sufficiency to dispense with it, the person who is poor and in need, and for the Muzakki, he treats himself in a small way and distorts the instinct of ownership, so that he becomes accustomed in giving and spending for zakat. The attempt to remove usury without activating the zakat foundation leads to a fundamental flaw in the Islamic finance process, To regulate or at the level of practice making usury tricks it appears as a necessity that can not escape them, though, in fact, the problem does not only make matters worse.

Keywords: Productive Zakat, Reduce Poverty, Improving the Economy, Society

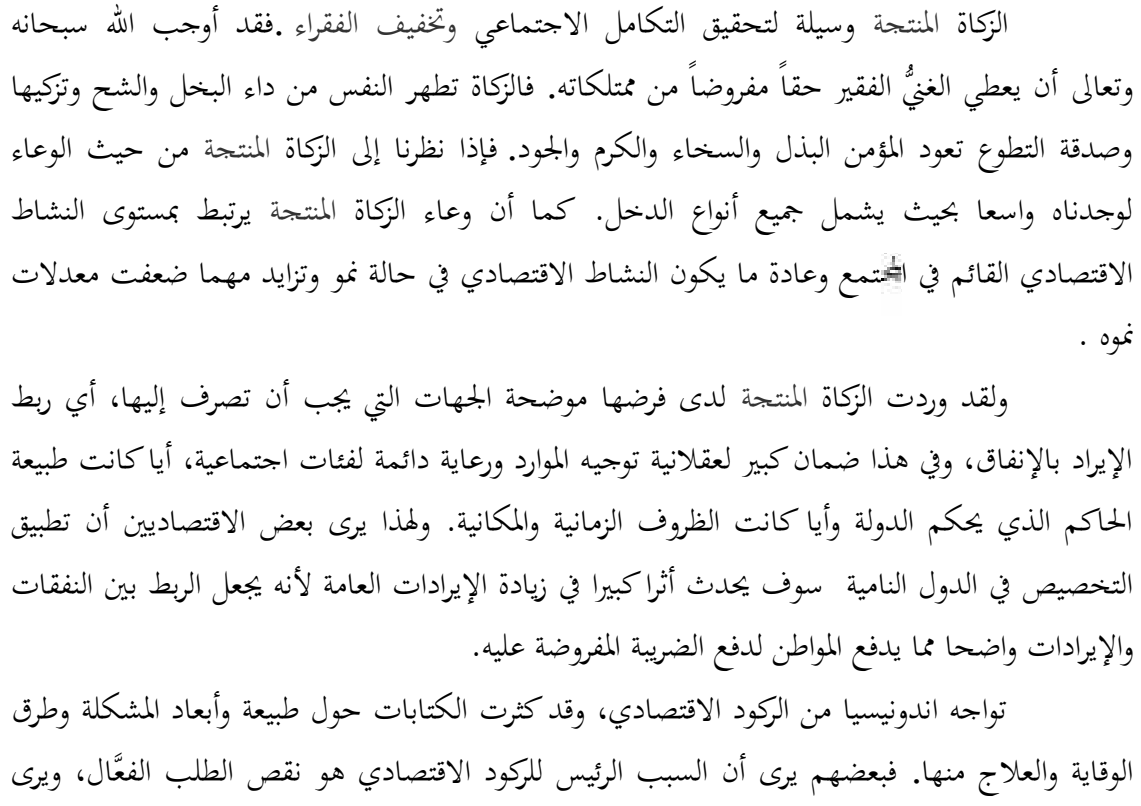




\section{Abdurrohman Kasdi}

آخرون أن من مظاهر الركود زيادة المخزون من السلع والبضائع وعدم وفاء التجار بالتزامائم المالية، إضافة

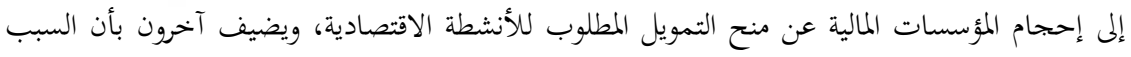

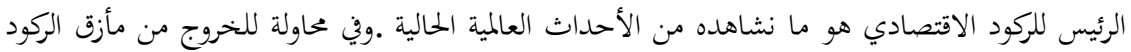
الاقتصادي، يعكف بعض الاقتصاديين على دراسة ما وضعه الاقتصادي الشهير كينز بضرورة التدخل

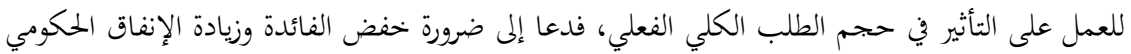

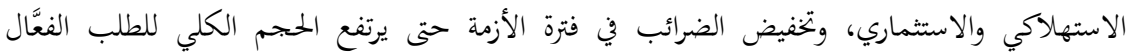
والاستثماري.

دراسة نظرية للزكاة المنتجة الزكاة من أهمّ أركان الإسلام بعد الصلاة، وهي التَطهّر والنظافة والنَّماء والزّيّادة .الزكاة احد من

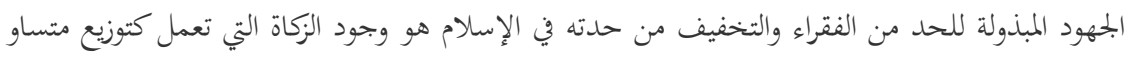

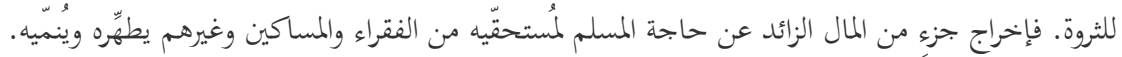

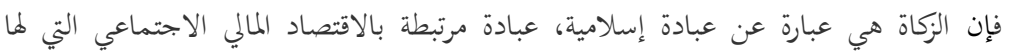

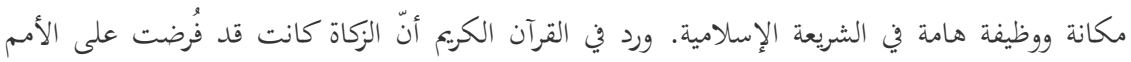

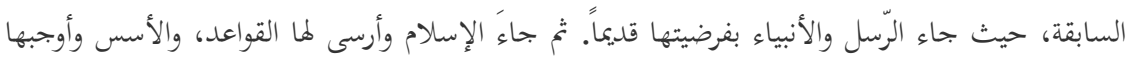

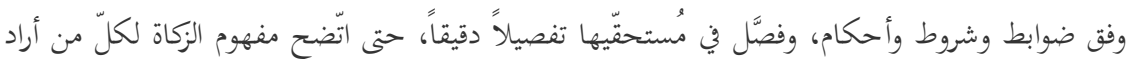

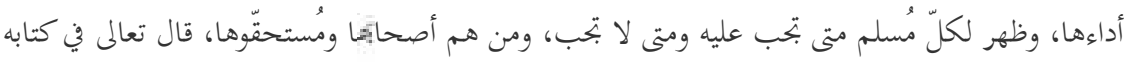

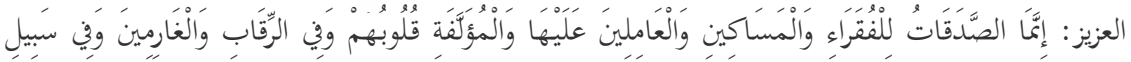

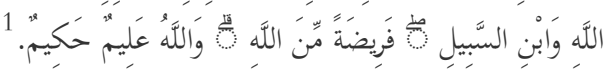

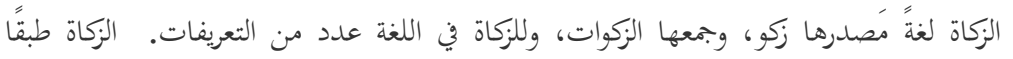

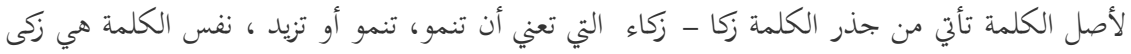

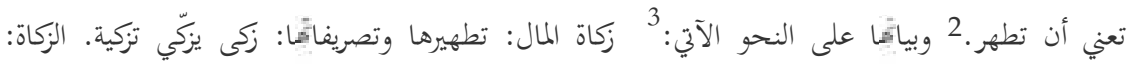

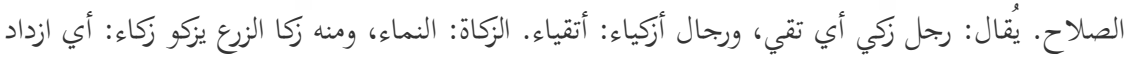

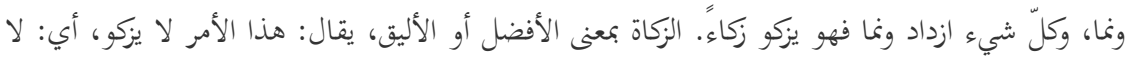

$$
1
$$

2 Ahmad Warson Munawwir, Kamus Al-Munawwir Arab-Indonesia, Pustaka Progresif, Surabaya, 1997, p. 577.

$$
\begin{aligned}
& \text { 3 أبو عبد الرحمن الخليل بن أحمد بن عمرو بن تميم الفراهيدي، كتاب العين، بيروت: دار } \\
& \text { ومكتبة الهالا، جزء 5. بتصرّف، صفحة } 394 .
\end{aligned}
$$


يَليق. قال الشاعر: والمال يزكو بك مستكبرا يختال قد أشرف للناظر سِّيّت الزكاة زكاةً للبرَكة التي تَظهر في

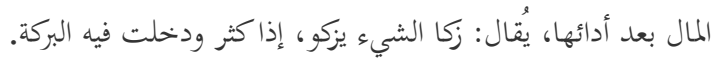

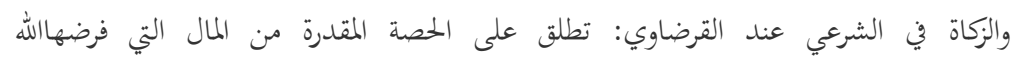

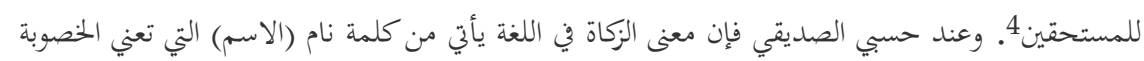

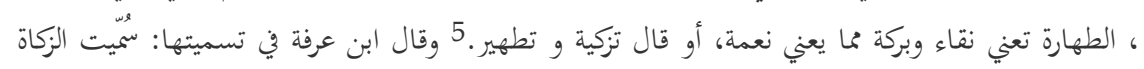

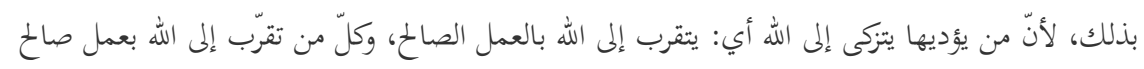

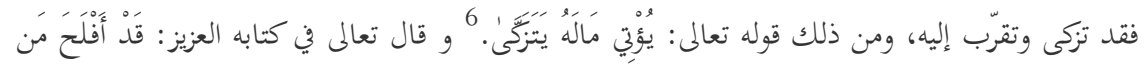

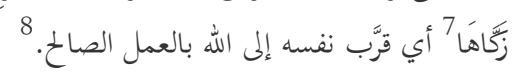
وحيث أنه وفقا للمصطلحات فإن الزكاة هي نشاط (العبادة) لإصدار بعض الأصول الرئيسية أو الو العمات المكونات الغذائية وفقا لأحكام الشريعة المعطاة لأشخاص معينين، في أوقات معينة مع مستويات معينة.

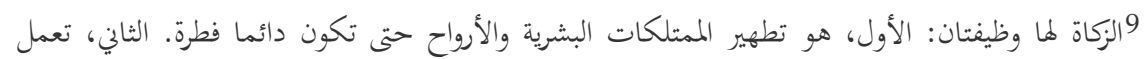

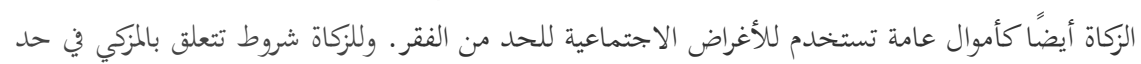
ذاته10، وفي المال الذي بتب الزكاة فيه. 11

4

${ }^{5}$ Hasbi Ash-Shiddieqy, Pedoman Zakat, Bulan Bintang, Jakarta, 1987, p. 24.

6

7

8 أبو عبيد أحمد بن محمد الهروي (1999)، الغريبين في القرآن والحديث (الطبعة الأولى)،

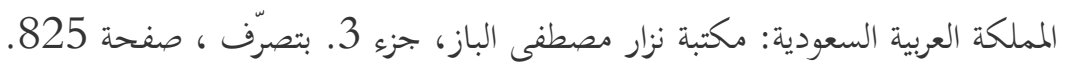

${ }^{9}$ BAZISKAF, Pedoman Manajemen Zakat, PT TELKOM Indonesia, 1997, p. 30

10 ميم أحمد الداغستاني ، "مصارف الزكاة في الشريعة الإسلامية، المطبعة الإسلامية

$$
\text { الحديثة"، مصر، 1992، 1992، صدئ 13-14. }
$$

11 النصاب هو المقدار المعين الذي لا بتجب الزكاة فيما دونه، فأقل نصاب الذهب عشرون

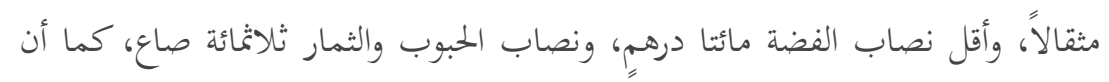
أقل نصاب الإبل خمسة، وأقل نصاب البقر ثلاثون، وأقل نصاب الغنم ثلاثون، ونصاب

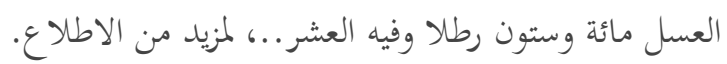




\section{Abdurrohman Kasdi}

عرّف العلماء الزكاة بأَّا حصّة مُقَدرة من المال فرضها الله عز وجل للمُستحقّين الذين سماهم في

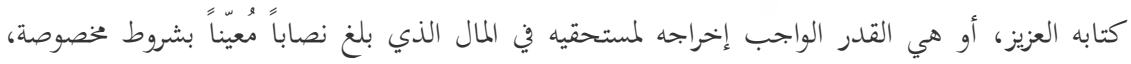

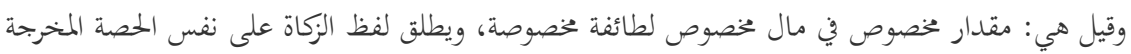

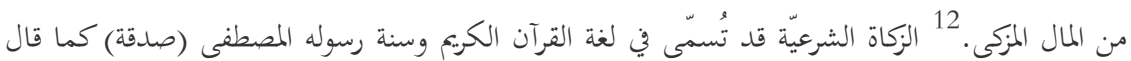

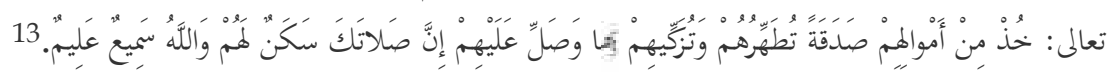

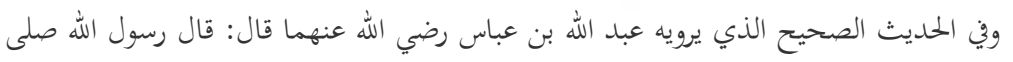

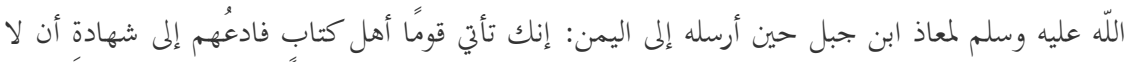

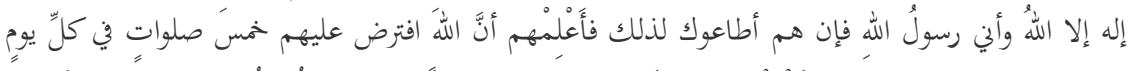

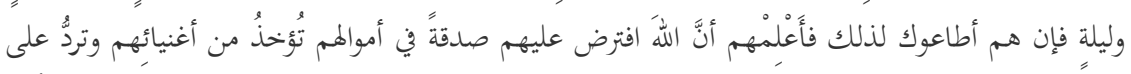

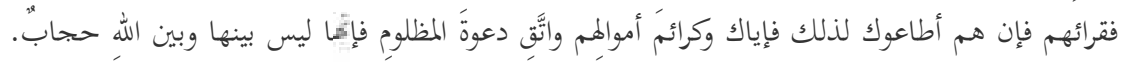

\section{حكم الزكاة ودليل مشروعيتها}

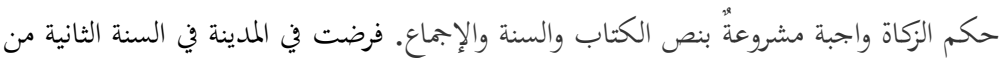

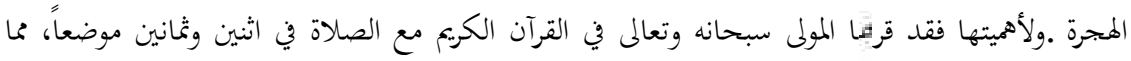

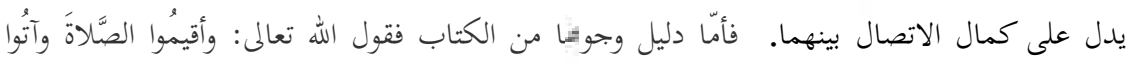

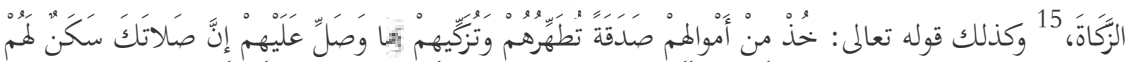

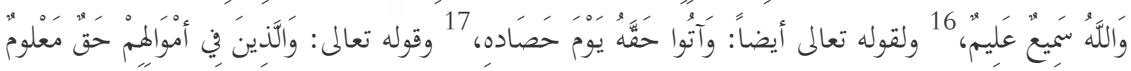

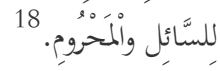

12 صالح بن غانم بن عبد الله بن سليمان بن علي السدلان (1425)، رسالة في الفقه الميسر (الطبعة الأولى)، المملكة العربية السعودية: وزارة الشؤون الإسلامية والأوقاف والدعوة والإرشاد، صفحة 59. بتصرّف. 13 سورة التوبة، آية: 103

14واه أبو داود، في سنن أبي داود، عن عبد الله بن عباس، الصفحة أو الرقم: 1584، 
اما الدليل وجوب الزكاة من السنة ما يرويه ابن عباس رضي اللّه عنهما قال: قال رسول الله

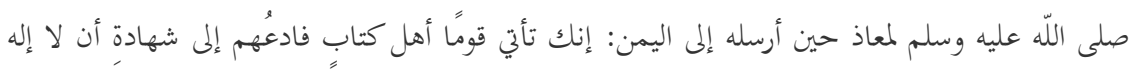

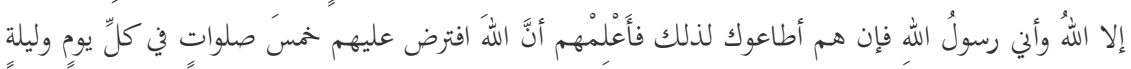

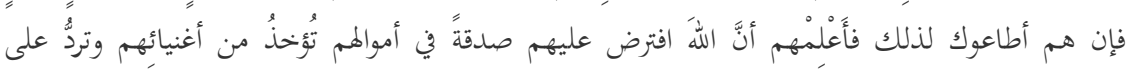

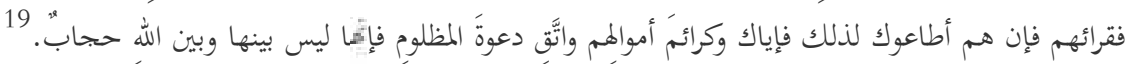
وقد أجمعت الأمة الإسلامية على وجوب الزكاة، وحرمة منعها. 20

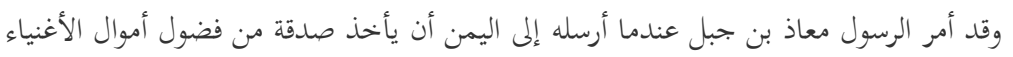

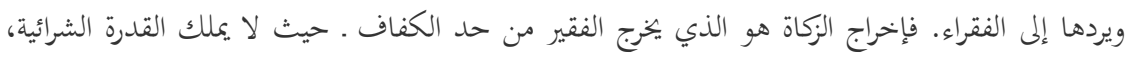

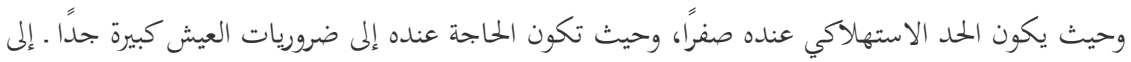
حد الكفاية، حيث تتوفر لديه القدرة الشرائية ويستطيع أن يساهم في الدورة الاقتصادية.

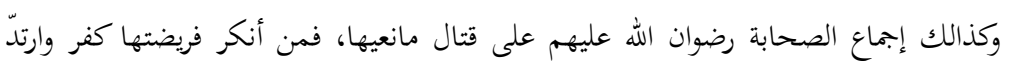

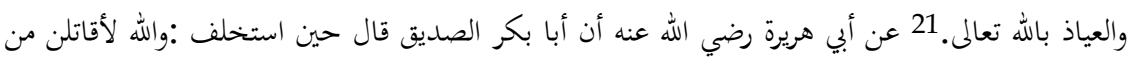

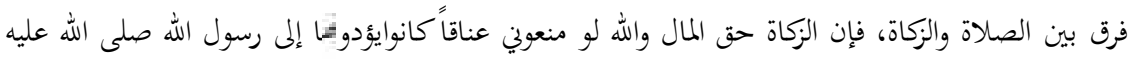

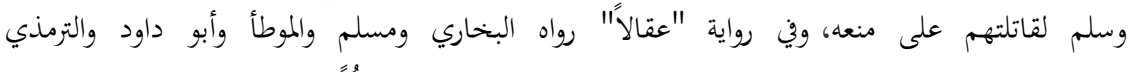

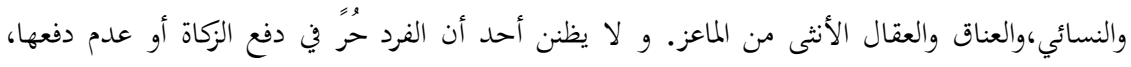
فالشارع يجبر ولي الأمر أخذها من مانعيها مع التغريم المالي قهراً عنهم.

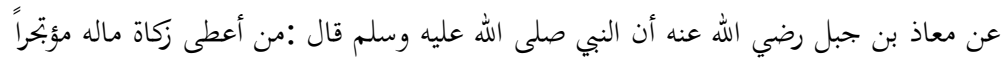

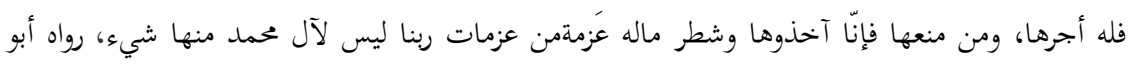
داود والنسائي عن معاذ. الزكاة تحفظ صاحبها من أهوال يوم القيامة فهي ظله حتى يتم حسابه، كما أنقا وقاية له من نار

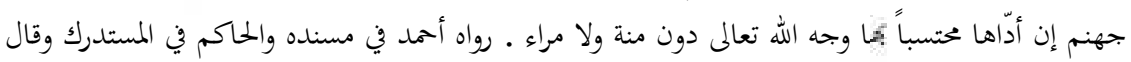

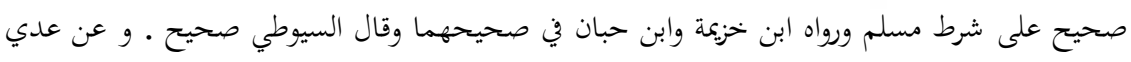

$$
17 \text { سورة الأنعام، آية: 141 سورة المعارج، آية: 24-25. }
$$

19 واه أبو داود، في سنن أبي داود، عن عبد الله بن عباس، الصفحة أو الرقم: 1584،

20 مشروعية الزكاة"، محلة البحوث الإسلامية، اطّلع عليه بتاريخ 2017/1/27. بتصرّف.

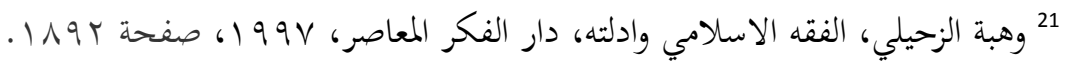




\section{Abdurrohman Kasdi}

بن حاتم قال:سمعت النبي صلى الله عليه وسلم يقول :من استطاع أن يستتر منكم من النار ولو بشق تمرة

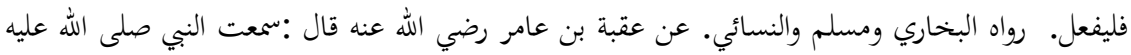
وسلم يقول :كل امرئ في ظل صدقته حتى يقضى بين الناس.

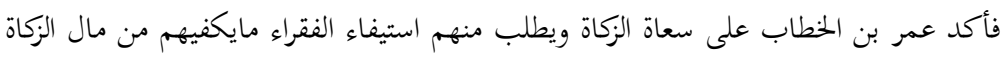

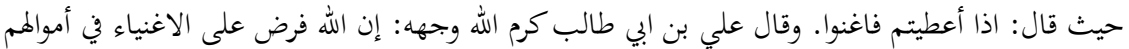

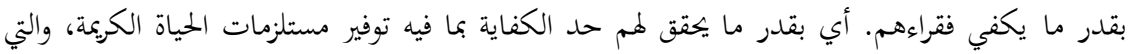

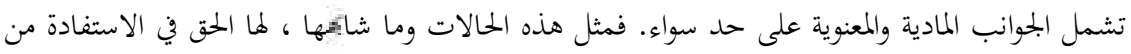

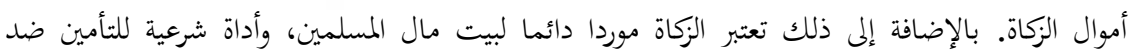

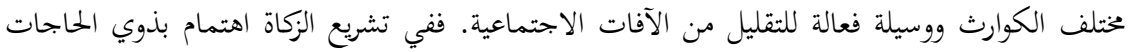

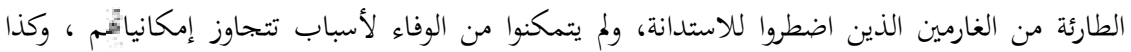
للاجئين والمشردين الذين أرغمتهم قسوة العيش وتقلبات الدهر للاستسلام للذل والبؤس.

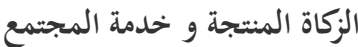

ما شرعت الزكاة إلا لخير اليتمع وتقدمه وتأمينه ضد العوارض والأزمات التي تعصف به أحيانا وتحصينه ضد كل ما يعيق رقيه وازدهاره ورفده بكل أسباب تشجيع الإنتاج وتحقيق التكافل ومحاربة البطالة.

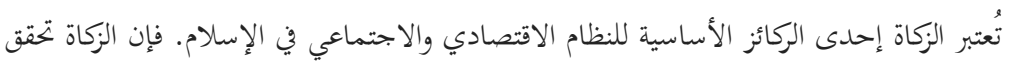

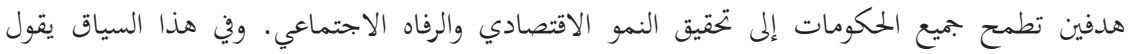

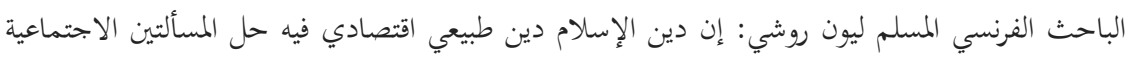

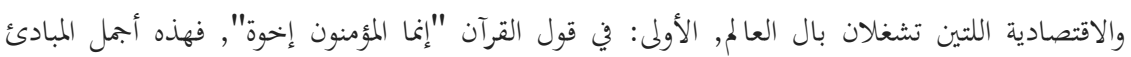

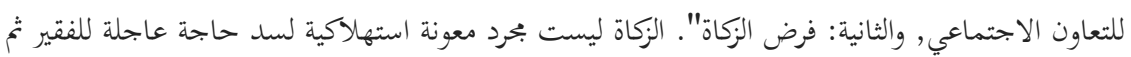
تركه بعد ذلك للفقر, بل هدفها في الإسلام القضاء على الفقر, من خلال تحويل الفقراء إلى طبقة عاملة فرداه

الزكاة تشريع إلهي، ومنهج تربوي، ومدرسة لتطهير النفس وتزكيتها ،وصقل للروح وقَذِيبها،

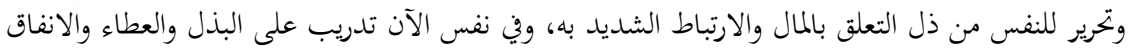

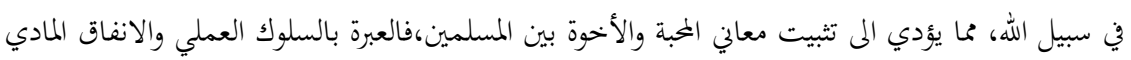

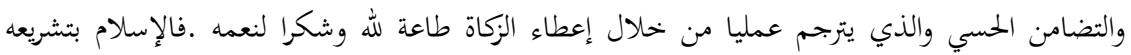

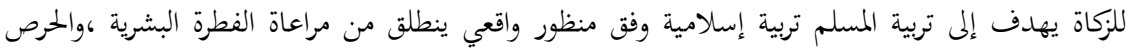

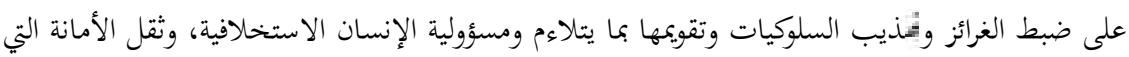
حملها بعدما أشفقت السماوات والأرض والجبال من حملها ، إقرارا بصعوبتها وتقديرا لأهميتها واعترافا بمكانتها. 
النظام الاقتصادي الإسلامي لا ينكر التفاوت بين الناس في المعايش والأرزاق، لأنه يعود إلى

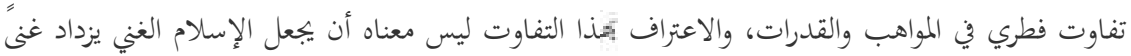

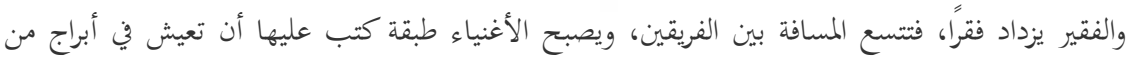

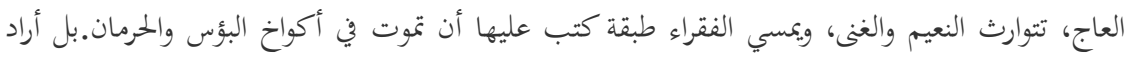

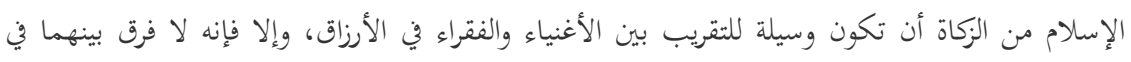

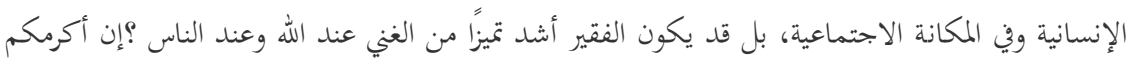
عند الله أتقاكم؟ الحجرات: 13. فإن للزكاة وظائف اقتصادية واجتماعية أخرى بالإضافة إلى دورها في التكافل الاجتماعي، منها:

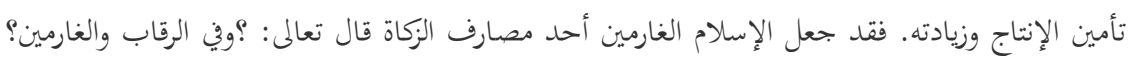

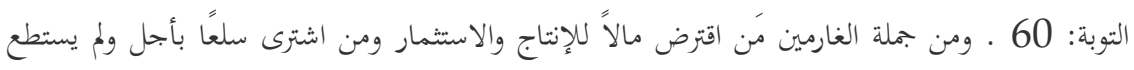

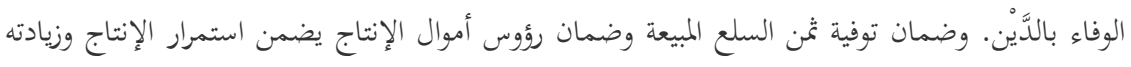
بازدياد المساهين في الإنتاج من غير أصحاب الأموال.

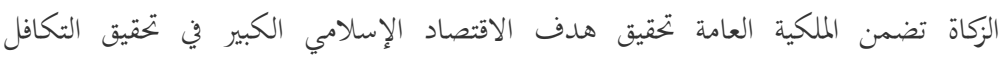

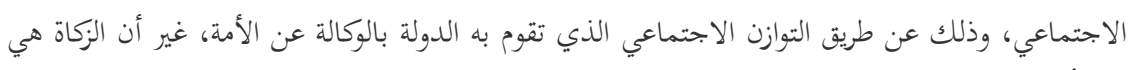

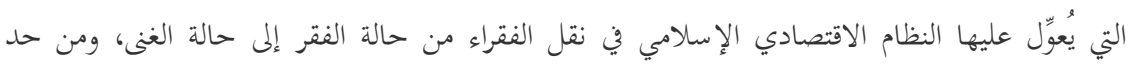
الكفاف إلى حد الكفاية.

الارتباط الحاصل بين الانفاق والاستثمار هو الذي يدعم حركة التنمية، ويضمن جديتها

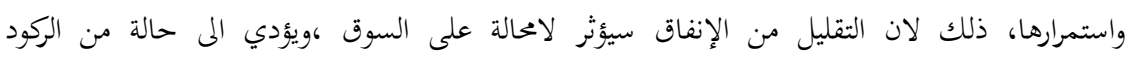

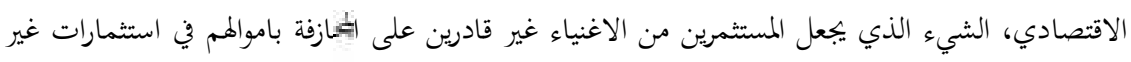

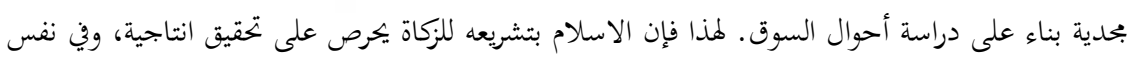

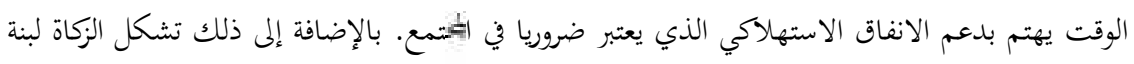

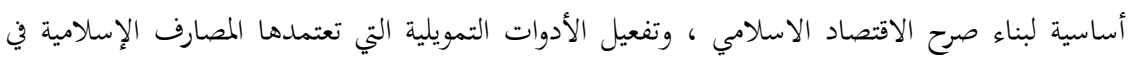

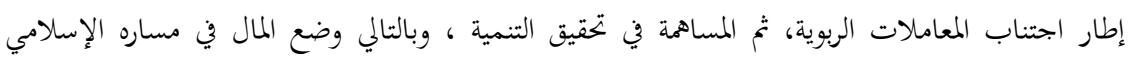

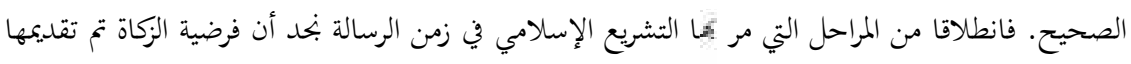

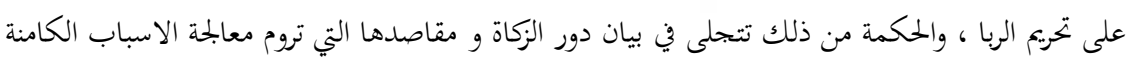

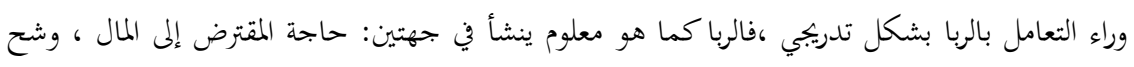

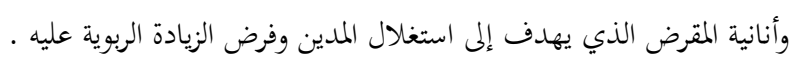

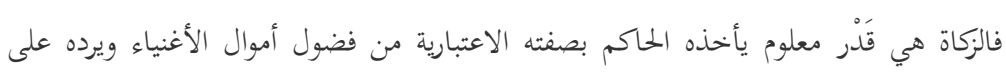

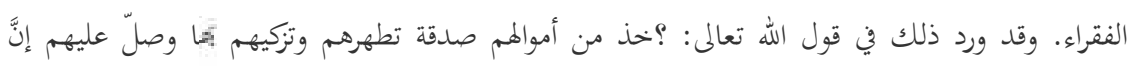




\section{Abdurrohman Kasdi}

صلاتك سكن لهم؟ التوبة: 103 ـ وفي قوله تعالى: ؟والذين في أموالهم حق معلوم للسائل والمحروم؟ المعارج:

إن هدف الزكاة هو إغناء الفقراء بالكلية وإخراجهم من الكفاف والحاجة إلى الكفاية الدائمة،

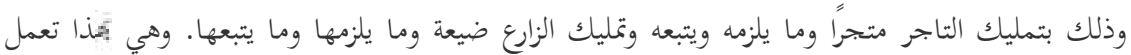

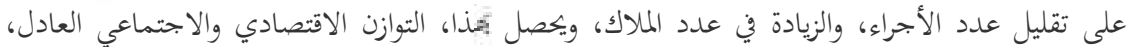

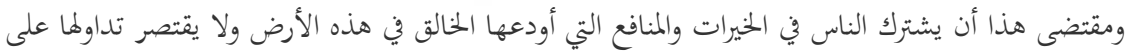
الأغنياء وحدهم

والقصد من الزكاة ليس سد حاجات الفقراء وإشباعها لبعض الوقت فقط، ولكن القصد منها

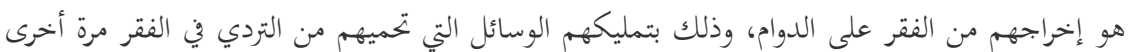

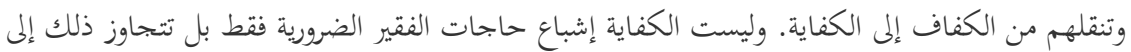

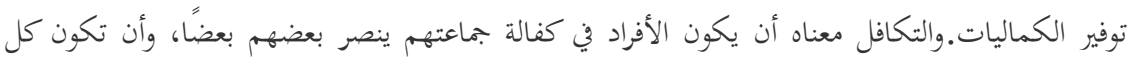

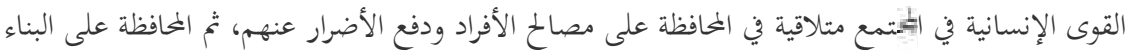

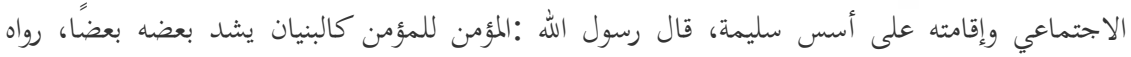

\section{الزكاة المنتجة وتخفيف الفقرأ}

ينتشر الفقر في العالم الإسلامي للعديد من الأسباب، لعل أهمها: الاستعمار الذي ثب ثروات

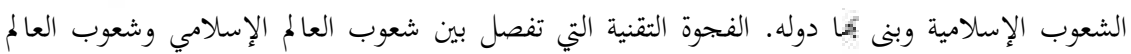

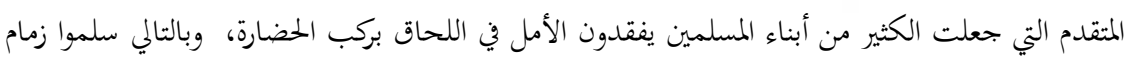

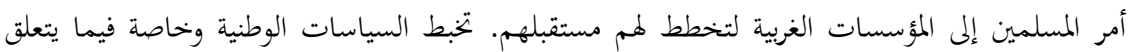
بمكافحة الفقر، وإهمال السياسة الإسلامية القائمة على فريضة الزكاة من المسلمين.

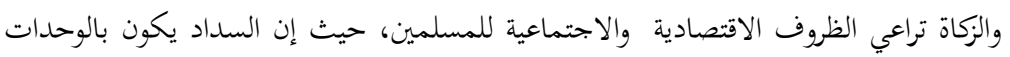

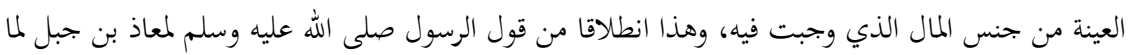
أرسله إلى اليمين: خذ الحب من الحبب والشاة من الغنم والبعير من الإبل والبقر من البقر ( رواه أبو داود ) مان.

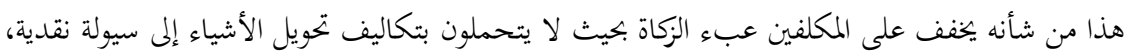

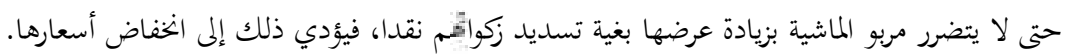
تقوم سياسة أندونيسيا في مكافحة الفقرأ على فرض الزكاة على الأغنياء وتوزيعها على الفقراء.

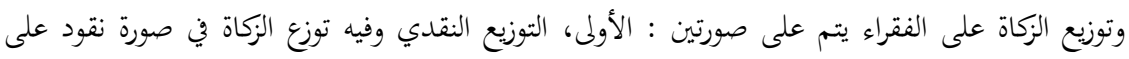

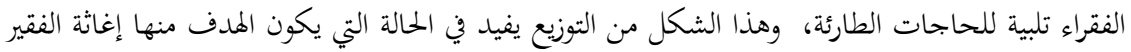




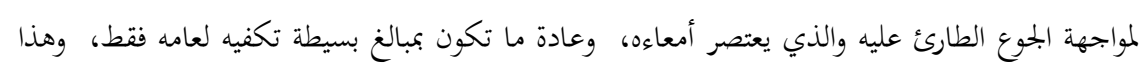

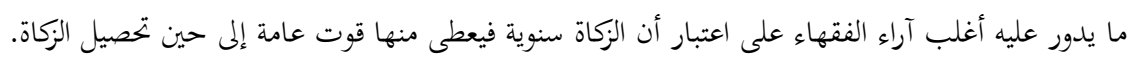

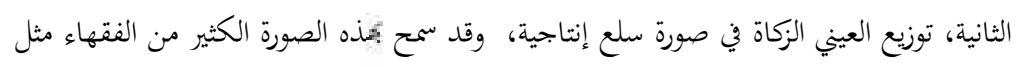

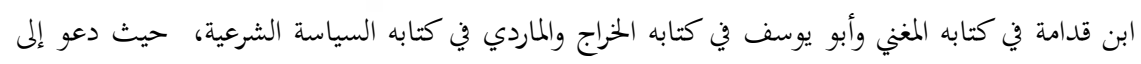

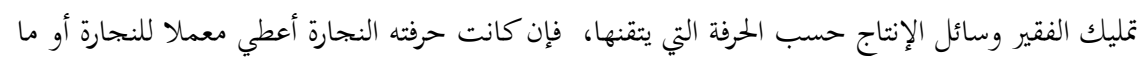

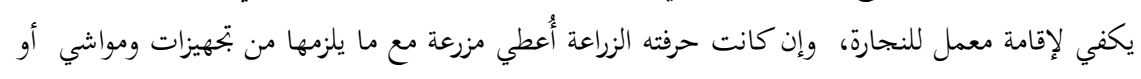
ما يكفي من المال لشراء ذلك كله.

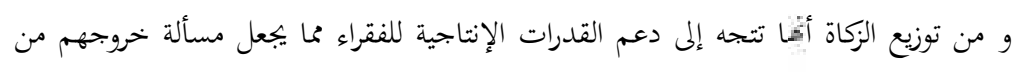

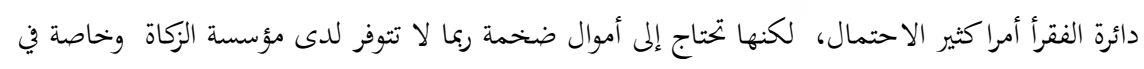

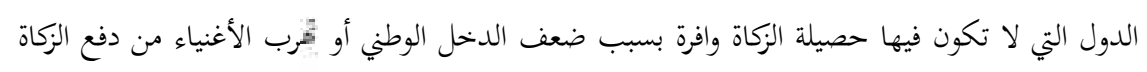
وهنا يبرز دور الدولة.

الزكاة المنتجة وتحسين الاقتصاد الاندونيسي

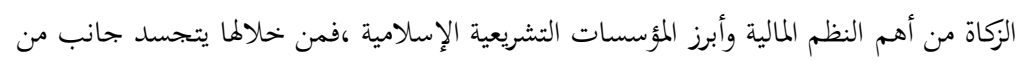

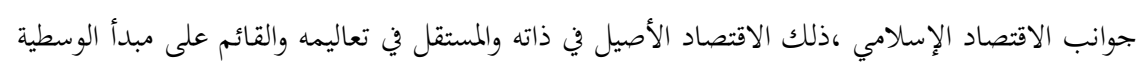

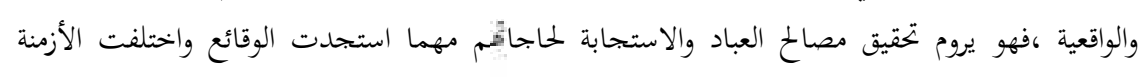

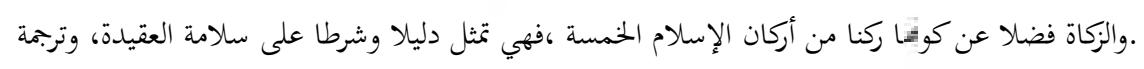

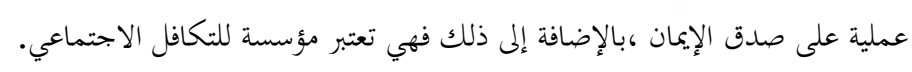

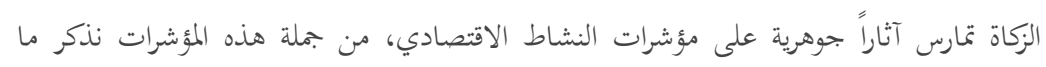

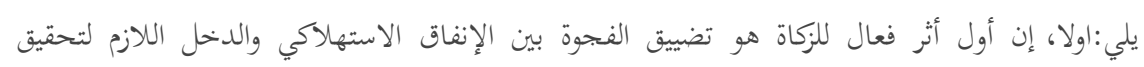

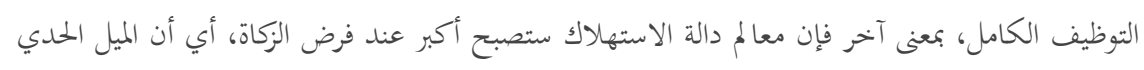

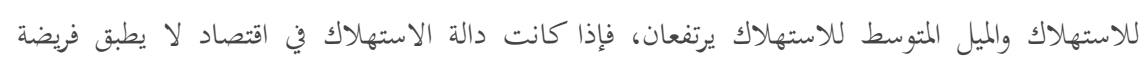

الزكاة. 22

ثانيا، تساعد الزكاة في تقعيق التنمية الاقتصادية في الختمع المسلم بصورة فاعلة عن طريق زيادة الإنتاج والاستثمار والتوظيف في الاقتصاد الوطني، وبلغة اقتصادية تقنية دقيقة، فإن منحنى إمكانيات الإنتاج

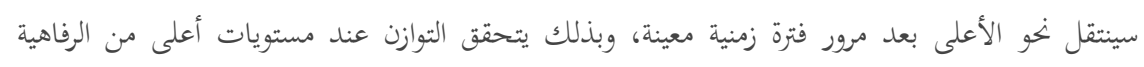

22 خليفي عيسى، "النفقات العامة للدولة في الاقتصاد الاسلامي"، بحلة الاقتصاد الاسلامي

$$
\text { العالمية، العدد 9، فيفري 2013، صليفي 16-20، }
$$




\section{Abdurrohman Kasdi}

الاجتماعية. الذي يَفْتَرضُ أن الاقتصاد الوطني ينتج بحموعتين من السلع، سلع ضرورية وسلع ترفيهية،

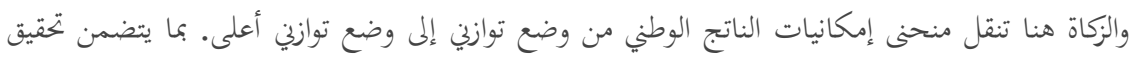

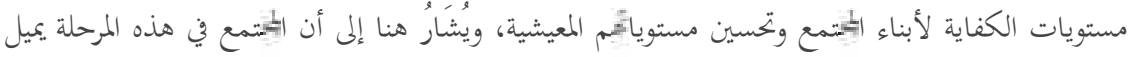
إلى الاتحاه نخو إنتاج السلع الضرورية أكثر من السلع الترفيهية. 23 قال الشيخ علي محي الدين القره داغي إن الدول الإسلامية تخلت عن واجبها في إلزام دفع

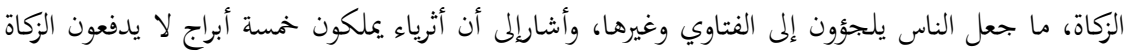

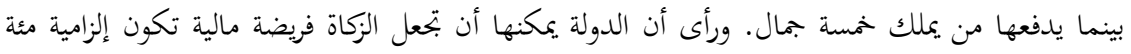

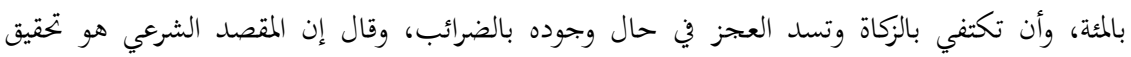

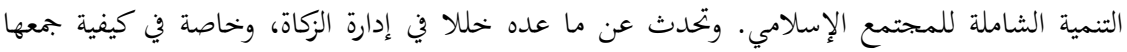
وصرفها.

فأن حصيلة الزكاة هي حصيلة مرتفعة ، وأنه بإمكانها أن تغطي الكثير من الحاجات الاجتماعية

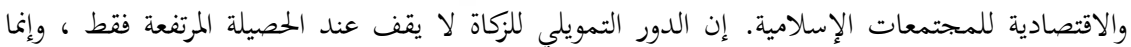

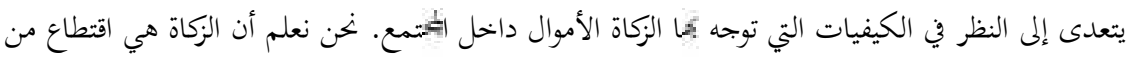

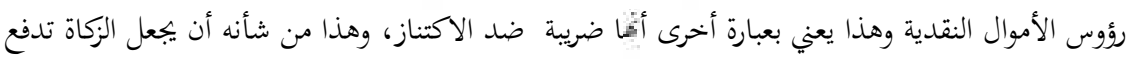

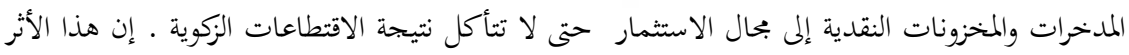

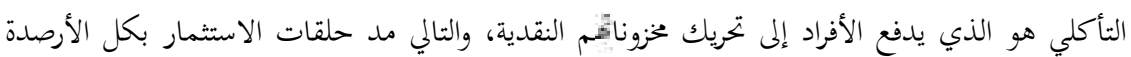

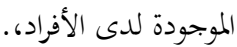

فالزكاة تُعد أداة أساسية في تحقيق عمارة الأرض من خحلال توفير الموارد التمويلية اللازمة للتنمية

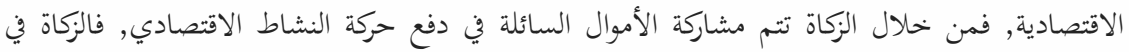

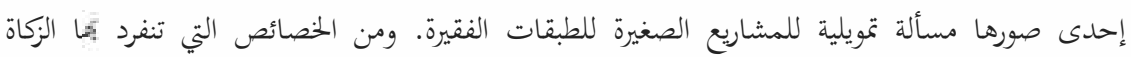
مساهمتها في معالجة ظاهرة البطالة. دور الزكاة الإيجابي في رفع مستوى الإنتاج من خلال محاربة البطالة، وتتجلى وظيفتها في الحرص

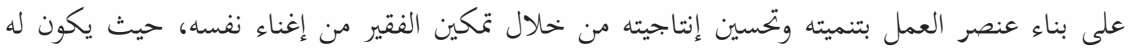

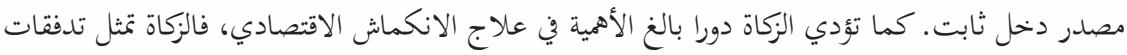

23 Munawar Iqbal, "Zakah, Moderation and Aggregate Consumption in An Islamic Economy," Journal of Research in Islamic Economics, King Abdulaziz University, Vol 3, No 1, Kingdom of Saudi Arabia, 1985, p. 4651.

${ }^{24}$ http://www.aljazeera.net/programs/economyandpeople/2015/7/18/- دور-الزكاة-a

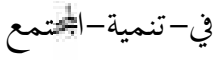


نقدية من الفئات الغنية إلى المستهلكين, ما ينعش الطلب على السلع الاستهلاكية في فترات الركود

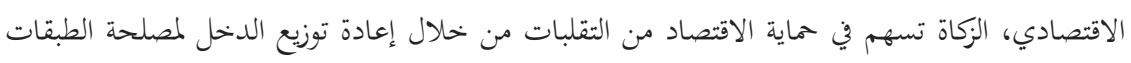

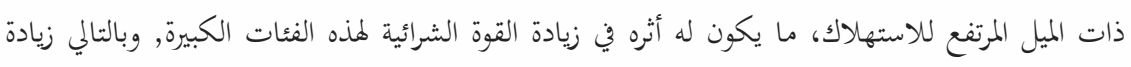

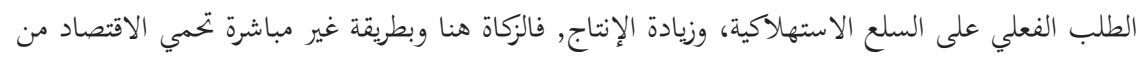
مخاطر الكساد. والزكاة أيضا وسيلة اقتصادية لتصحيح الخلل الطبيعي في توزيع الثروات.

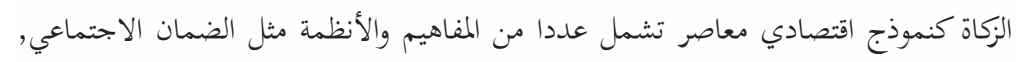

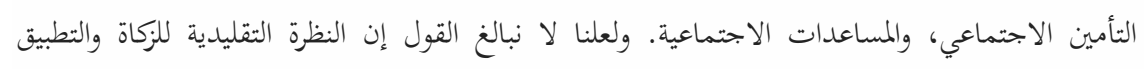
العشوائي لها جعلا هذه الفريضة لا تأخذ حقها من الاهتمام في الواقع الاقتصادي المعاصر.

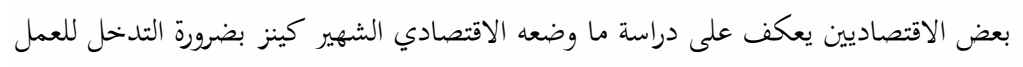
على التأثير في حجم الطلب الكلي الفعلي، فدعا إلى ضرورة خفض الفائدة وزيادة الإنفاق الحكومي

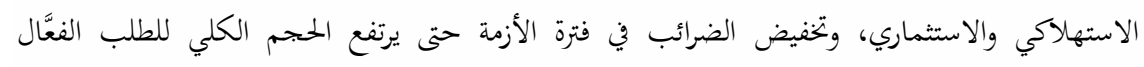

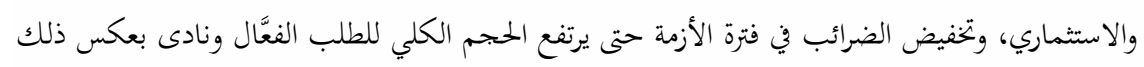

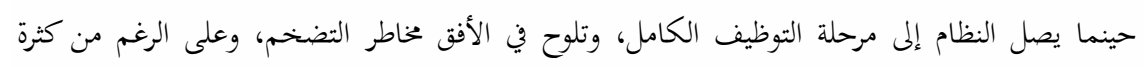

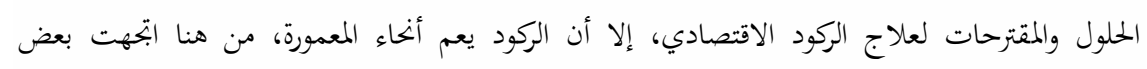

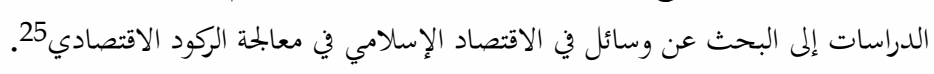

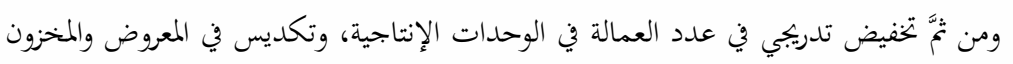

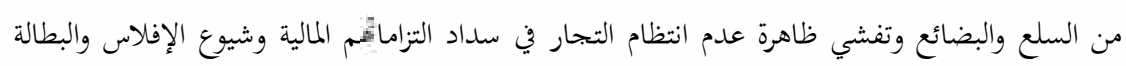

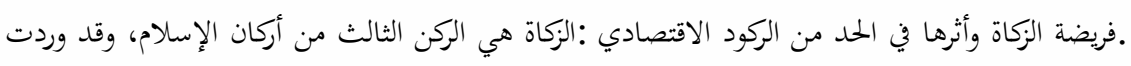

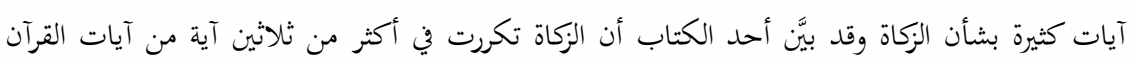

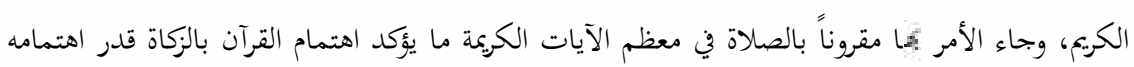
بالصلاة26.

\section{الخا تمة}

ألزكاة مؤسسة للتكافل الاجتماعي والذي يعد من أهم الأسس التي يقوم عليها اليتمع، فهو

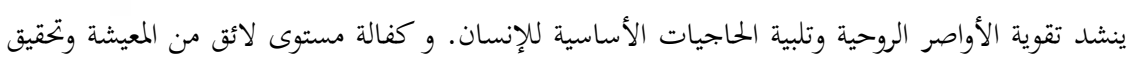

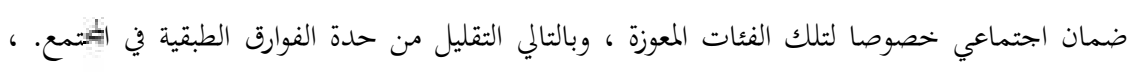

25 انظر أ.عمر عبد الله كامل، الركود وسبل معالجته في الاقتصاد الإسلامي. 26 انظر أ .عبد الرزاق نوفل . فريضة الزكاة .ص. 


\section{Abdurrohman Kasdi}

ففي إخراجها سد خلة المحتاجين وحفظ كرامتهم، وصون عفتهم ، وتخفيف من معاناقَم النفسية وحماية لمم

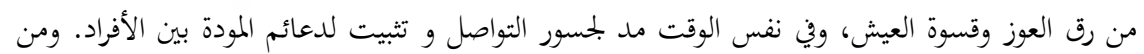

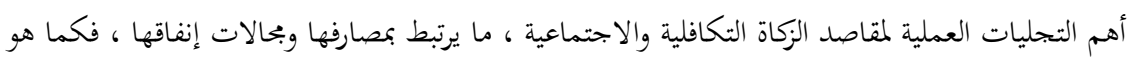
معلوم يتم تخصيص جزء من أموال الزكاة لضمان وسد الحاجات الضرورية ذات الطابع الاستهلاكي لفئة من

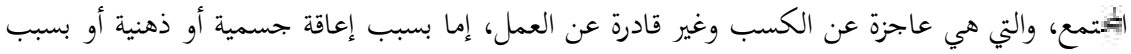

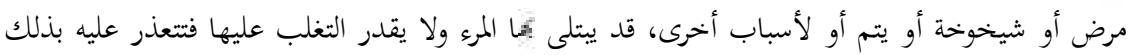
سبل العيش الكريم.

أن أموال الزكاة تتوجه بنسبة كبيرة لصالح الطبقات المحرومة، التي يكون ميلها الحدي للاستهالك كئك

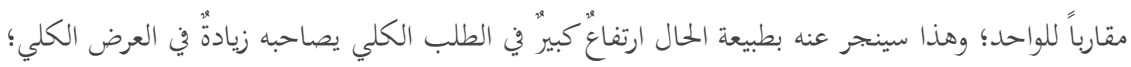

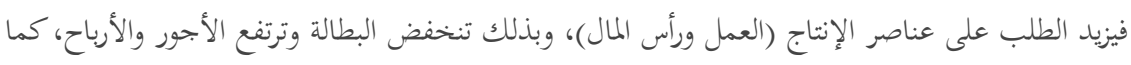

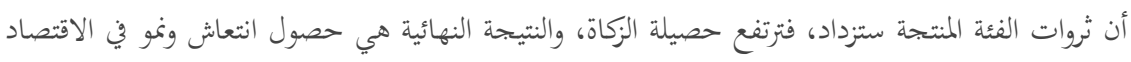

تعتبر الزكاة جزءا من النظام الاقتصادي الإسلامي ،فهي حجر الزاوية في بناء هذا النظام

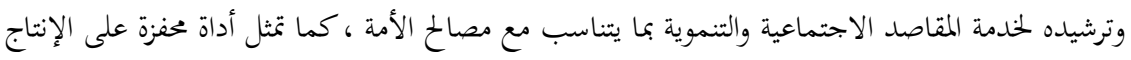

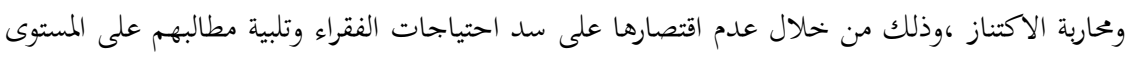

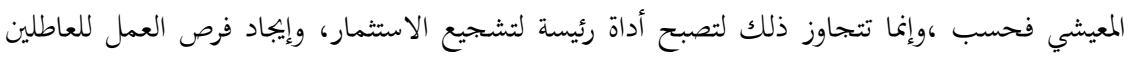

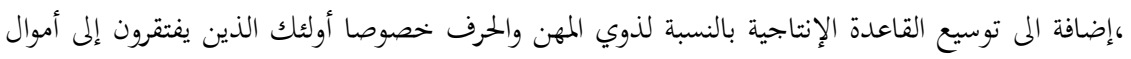

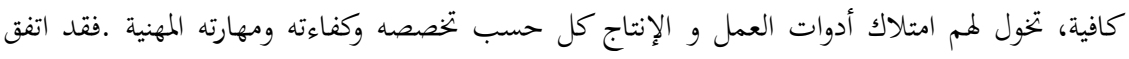

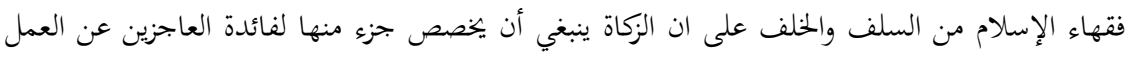

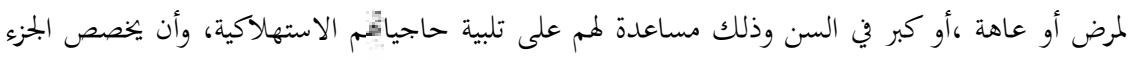

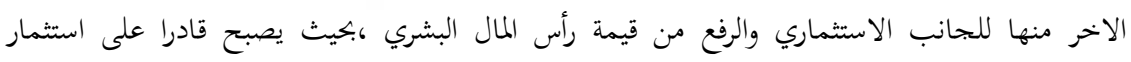

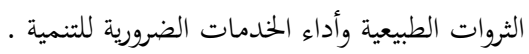

\section{المصادر والمراجع}

أبو عبد الرحمن الخليل بن أحمد بن عمرو بن تميم الفراهيدي، كتاب العين، بيروت: دار ومكتبة الهلال، جزء واجع

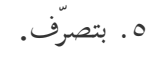

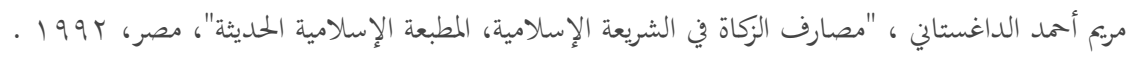
أبو عبيد أحمد بن محمد الهروي، الغريبين في القرآن والحديث (الطبعة الأولى)، المملكة العربية السعودية:

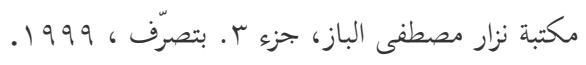


صالخ بن غانم بن عبد الله بن سليمان بن علي السدلان ، رسالة في الفقه الميسر (الطبعة الأولى)، المملكة

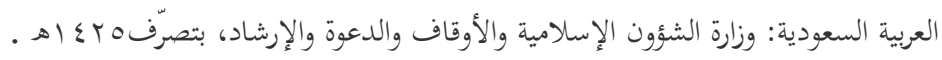

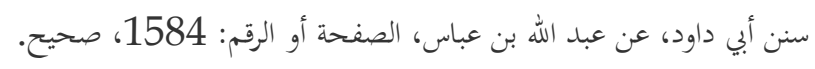

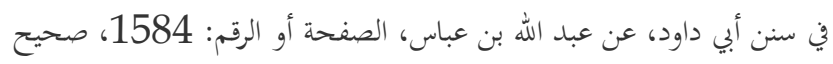

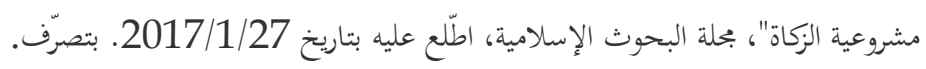

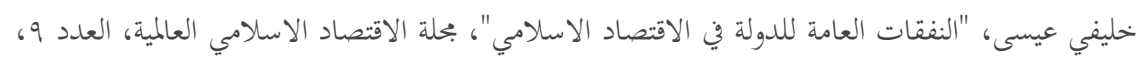

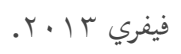

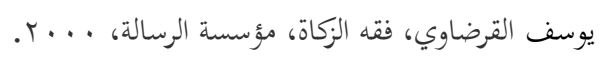

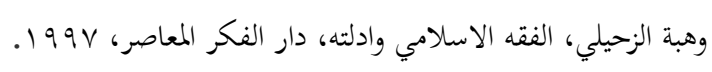

Munawwir, Ahmad Warson, Kamus Al-Munawwir ArabIndonesia, Pustaka Progresif, Surabaya, 1997. Ash-Shiddieqy, Hasbi, Pedoman Zakat, Bulan Bintang, Jakarta, 1987.

BAZISKAF, Pedoman Manajemen Zakat, PT TELKOM Indonesia, 1997.

http://www.aljazeera.net/programs/economyandpeople/2 دور -الزكاة-في-تنمية-الغتمع 015/7/18

Munawar Iqbal, “Zakah, Moderation and Aggregate

Consumption in An Islamic Economy," Journal of Research in Islamic Economics, King Abdulaziz University, Vol 3, No 1, Kingdom of Saudi Arabia, 1985. 